\title{
Intracellular pH determination of pristinamycin-producing Streptomyces pristinaespiralis by image analysis
}

\author{
P. F. X. Corvini, ${ }^{1}$ H. Gautier, ${ }^{1}$ E. Rondags, ${ }^{1}$ H. Vivier, ${ }^{2}$ J. L. Goergen ${ }^{2}$ \\ and P. Germain ${ }^{1}$
}

Author for correspondence: J. L. Goergen. Tel: +33 3835958 44. Fax: +33 383595796. e-mail: Jean-Louis.goergen@ensaia.inpl-nancy.fr

Laboratoire de

Fermentations et de

Bioconversions Industrielles ${ }^{1}$, and Laboratoire des Sciences du Génie Chimique - CNRS2, Institut National

Polytechnique de Lorraine,

2 Avenue de la Forêt

de Haye, BP 172, F-54505

Vandoeuvre-lès-Nancy,

France

\begin{abstract}
Intracellular $\mathrm{pH}\left(\mathrm{pH}_{\mathrm{i}}\right)$ is an essential parameter in the regulation of intracellular processes. Thus, its measurement might provide clues regarding the physiological state of cells cultivated in vitro. $\mathrm{pH}_{\mathrm{i}}$ of the filamentous, pristinamycin-producing Streptomyces pristinaespiralis was determined by epifluorescence microscopy and image analysis using the pH-sensitive fluorescent probe BCECF-AM [2',7'-bis(2-carboxyethyl)-5(6)-carboxyfluorescein, acetoxymethyl ester]. Staining cell culture samples $\left(O D_{660}=1\right)$ of $S$. pristinaespiralis with $20 \mu \mathrm{M}$ BCECF at $28{ }^{\circ} \mathrm{C}$ for $30 \mathrm{~min}$ yielded a green/red fluorescence ratio $\left(R_{5271600}\right)$ that correlated with the $\mathrm{pH}_{\mathrm{i}}$ of the cells for values ranging from 6.5 to 8.5 . When $S$. pristinaespiralis was cultivated in pristinamycin-producing conditions (in batch mode, with a constant external $\mathrm{pH}$ of 6.8), the measured $\mathrm{pH}_{\mathrm{i}}$ varied between 6.3 and 8.7. In fact, $\mathrm{pH}_{\mathrm{i}}$ correlated with the excretion of pristinamycins and glucose consumption during the production process.
\end{abstract}

Keywords: intracellular $\mathrm{pH}$, Streptomyces pristinaespiralis, epifluorescence microscopy, image analysis

\section{INTRODUCTION}

Pristinamycins belong to the synergistin family of antibiotics and are composed of two distinct groups of molecules, pristinamycins $\mathrm{I}\left(\mathrm{P}_{\mathrm{I}}\right)$ and pristinamycins II $\left(\mathrm{P}_{\mathrm{II}}\right)$ (Preud'homme et al., 1968), which act synergistically to exert their bactericidal action. For example in therapy against Staphylococcus aureus infection it has been found that the most efficient ratio is $60 \%$ $\mathrm{P}_{\text {II }} / 40 \% \mathrm{P}_{\mathrm{I}}$ (Videau, 1982). As for two-thirds of all antibiotics, pristinamycins are produced, in batch process, by a filamentous bacterium of the genus Streptomyces (Demain, 1999), namely Streptomyces pristinaespiralis (Rhône-Poulenc, 1961).

Because there has been an ever-increasing demand for antibiotics (new molecules and higher doses) over the last decade (Craig, 1996), the optimization of the existing processes and the modification (improvement) of bacterial strains by genetic engineering (Baltz, 1998) are of great interest. Fine optimization of the pristin-

Abbreviations: BCECF-AM, 2',7'-bis(2-carboxyethyl)-5(6)-carboxyfluorescein, acetoxymethyl ester; $\mathrm{pH}_{\mathrm{i}}$, intracellular $\mathrm{pH} ; R_{527 / 600}$, green/red fluorescence ratio $(527 / 600 \mathrm{~nm})$. amycin production process requires good knowledge of cell physiology during the fermentation. In the context of studies on the physiology of actinomycetes, research teams have focused on metabolic changes occurring when antibiotic biosynthesis takes place under the influence of numerous external factors (Paquet, 1990; Demain, 1972). Assuming the existence of a close link between morphology and secondary metabolite production, most reports on image analysis of filamentous micro-organisms, including Streptomyces, present their morphology (Paul \& Thomas, 1998; Cox et al., 1998; Yang et al., 1996). Because Streptomyces filaments can have different morphologies (filaments, clumps and pellets), depending on culture conditions and the physiological state of cells, separate studies have been required to investigate the relationship between each morphological type and metabolite production by image analysis (Drouin et al., 1997; Durant et al., 1994a, b; Cox \& Thomas, 1992). In addition, image analysis has been used to determine the location of respiration activity in Streptomyces ambofaciens filaments (Mauss et al., 1997) and the leakage of cellular components through the membrane of $S$. ambofaciens using carbon gentian violet staining (Pons et al., 1998). 
Among the parameters controlling metabolic activities, intracellular $\mathrm{pH}\left(\mathrm{pH}_{\mathrm{i}}\right)$ plays a major role in the regulation of enzyme activities and transport kinetics of nutrients and metabolites. Furthermore, the $\mathrm{pH}$ gradient across cell membranes $(\Delta \mathrm{pH})$ is related to cellular energetic mechanisms such as ATP generation (Leyval et al., 1997; Imai \& Ohno, 1995). $\mathrm{pH}_{\mathrm{i}}$ assessment in eukaryotic cells is now well documented in the literature; fluorescent probes coupled to spectrofluorometric methods and image analysis techniques have been successfully used to investigate $\mathrm{pH}_{\mathrm{i}}$ of several cell lines (Heiple \& Taylor, 1980; Slavik, 1983; Paradiso et al., 1987; Dix \& Verkman, 1990; Cherlet et al., 1999). On the other hand, $\mathrm{pH}_{\mathrm{i}}$ determination in prokaryotic cells by means of flow cytometry (Leyval et al., 1997) or microscopy coupled to image analysis tools (Siegumfeldt et al., 1999) remains sparse and $\mathrm{pH}_{\mathrm{i}}$ assessment in filamentous bacteria, such as $S$. pristinaespiralis, has not been reported so far. Due to a limited resolution time for distribution measurement of labelled weak acids or bases and NMR methods, other techniques must be considered for such studies. However, because most Streptomyces species tend to grow as pellet and filamentous forms in submerged culture (Whitaker, 1991), flow cytometry cannot be used. Therefore, epifluorescence microscopy combined with image analysis has emerged as an alternative method.

In this study a protocol was developed for $\mathrm{pH}_{\mathrm{i}}$ measurement in the pristinamycin-producing species $S$. pristinaespiralis by epifluorescence microscopy and image analysis using the fluorochrome BCECF-AM $\left[2^{\prime}, 7^{\prime}-\right.$ bis(2-carboxyethyl)-5(6)-carboxyfluorescein, acetoxymethyl ester]. A second consideration concerns the methodology applied to monitor the variations of $\mathrm{pH}_{\mathrm{i}}$ during pristinamycin-producing batch culture of $S$. pristinaespiralis.

\section{METHODS}

Bacterial strain. Streptomyces pristinaespiralis mutant strain Pr11 was used for all experiments and was obtained from the Rhône-Poulenc-Rorer research centre, Vitry sur Seine, France.

Media. The following media were used in this study. Complex medium $\left(\mathrm{g} \mathrm{l}^{-1}\right)$ : sucrose, 15; corn steep (Roquette), 5; $\left(\mathrm{NH}_{4}\right)_{2} \mathrm{SO}_{4}, 10 ; \mathrm{K}_{2} \mathrm{HPO}_{4}, 1 ; \mathrm{NaCl}, 3 ; \mathrm{MgSO}_{4} .7 \mathrm{H}_{2} \mathrm{O}, 0 \cdot 2$; $\mathrm{CaCO}_{3}, 1 \cdot 25 ; \mathrm{pH} 6 \cdot 8$; sterilized for $20 \mathrm{~min}$ at $120^{\circ} \mathrm{C}$. Synthetic medium $\left(\mathrm{g}^{-1}\right)$ : glucose, 30 ; malonic acid, $7 \cdot 5$; L-arginine, 3 ; Lglutamate, $1.5 ; \mathrm{K}_{2} \mathrm{HPO}_{4}, 0.75 ; \mathrm{MgSO}_{4} .7 \mathrm{H}_{2} \mathrm{O}, 0 \cdot 3 ; \mathrm{FeSO}_{4}$. $7 \mathrm{H}_{2} \mathrm{O}, 15 ; \mathrm{ZnSO}_{4} .7 \mathrm{H}_{2} \mathrm{O}, 0.55 ; \mathrm{CaCl}_{2} .2 \mathrm{H}_{2} \mathrm{O}, 0.4 ; 3$-morpholinopropanesulfonic acid, $20 ; \mathrm{pH} 6.8$; sterilized for $20 \mathrm{~min}$ at $110{ }^{\circ} \mathrm{C} . \mathrm{K}_{2} \mathrm{HPO}_{4}$ and $\mathrm{CaCl}_{2}$ in concentrated solutions were sterilized by filtration on $0 \cdot 22 \mu \mathrm{m}$ filters (Millipore) and added separately to avoid precipitation. All chemicals were analytical grade.

Culture conditions. Inocula were prepared by pouring $0.8 \mathrm{ml}$ of a thawed spore solution calibrated at $3 \times 10^{8}$ c.f.u. $1^{-1}$ into $500 \mathrm{ml}$ baffled shake flasks containing $80 \mathrm{ml}$ complex medium. Flasks were shaken at 250 r.p.m. and $28{ }^{\circ} \mathrm{C}$ for $44 \mathrm{~h}$ using an orbital shaker (Ika).

Bacteria used during the experiments dedicated to method development were grown in $300 \mathrm{ml}$ Erlenmeyer flasks, whereas monitoring of $\mathrm{pH}_{\mathrm{i}}$ of pristinamycin-producing $S$. pristin- aespiralis was performed on cultures grown in a 21 bioreactor (CMF 100; Alpha-Laval-Chemap). Inocula (2 ml) were poured into $250 \mathrm{ml}$ Erlenmeyer flasks containing $30 \mathrm{ml}$ synthetic medium. Cells were grown with agitation at 250 r.p.m. and $28^{\circ} \mathrm{C}$. For bioreactor batch cultures, $80 \mathrm{ml}$ preculture was inoculated into 21 synthetic medium at $28^{\circ} \mathrm{C}$. The oxygen level was maintained at a minimum of $30 \%$ of air saturation and controlled through stirring conditions. Agitation with Rushton impellers ranged between 300 and 1500 r.p.m.

Cell staining. All experiments were carried out at $4{ }^{\circ} \mathrm{C}$ in a dark room. Stock solutions ( $50 \mu \mathrm{l}$ samples) of $1 \mathrm{mM}$ BCECFAM (Molecular Probes) in DMSO were stored in the dark at $-20^{\circ} \mathrm{C}$. Culture samples were directly diluted in PBS to obtain a final $\mathrm{OD}_{660}$ of $1 \cdot 0$. Cells were incubated at $28^{\circ} \mathrm{C}$ on a rotary shaker with different concentrations of BCECF-AM $(2 \cdot 5-50 \mu \mathrm{M})$ for incubation times ranging from 0 to $40 \mathrm{~min}$.

In vivo calibration. The $\left[\mathrm{H}^{+}-\mathrm{K}^{+}\right]$carboxylic ionophore nigericin and neutral ionophore valinomycin (Sigma) were used for $\mathrm{pH}_{\mathrm{i}}$ calibration as described elsewhere (Musgrove et al., 1986; Pressman, 1976). Nigericin was dissolved in absolute ethanol and valinomycin in DMSO at final concentrations of 1 and $10 \mathrm{mM}$, respectively. Both solutions were stored at $-20^{\circ} \mathrm{C}$. The cells used for the establishment of calibration curves were stained as described above. After a 30 s centrifugation at $6000 \mathrm{~g}$ and the removal of supernatant, cells were resuspended in high $\left[\mathrm{K}^{+}\right]$buffers at different $\mathrm{pH}$ values $(6 \cdot 5-8 \cdot 5)$. High $\left[\mathrm{K}^{+}\right]$buffers were obtained by mixing appropriate quantities of $135 \mathrm{mM} \mathrm{KH}_{2} \mathrm{PO}_{4} / 20 \mathrm{mM} \mathrm{NaOH}$ and $110 \mathrm{mM} \mathrm{K} \mathrm{K}_{2} \mathrm{HPO}_{4} / 20 \mathrm{mM} \mathrm{NaOH}$. Buffer solutions were filtered before use through $0 \cdot 22 \mu \mathrm{M}$ filters and stored at $4{ }^{\circ} \mathrm{C}$. When stated, osmolality of each buffered solution (measured with a Roebling osmometer) was adjusted to that of the fermentation broth by adding xylose. Nigericin was added at a final concentration ranging from 5 to $40 \mu \mathrm{M}$ for $10 \mathrm{~min}$. Valinomycin was added simultaneously to $20 \mu \mathrm{M}$ nigericin at concentrations varying from 0 to $10 \mu \mathrm{M}$ for different incubation times $(5-30 \mathrm{~min})$. Cells were then centrifuged again as described above, resuspended in the same high $\left[\mathrm{K}^{+}\right]$buffer and kept on ice.

Double emission ratio technique. An epifluorescent microscope (DMRB; Leica Leitz) with $\times 10$ magnification and a 0.30 numerical aperture PL Fluotar objective was used. The final magnification was $\times 100$, because of the camera and the $\times 10$ magnification of the objective. The light source was a $50 \mathrm{~W} \mathrm{Hg}$ lamp (Osram). Excitation and emission band pass filters were assembled. Whereas the excitation filter was the same for both modules $(480 / 40 \mathrm{~nm})$, two different emission filters were used: $527 / 30 \mathrm{~nm}$ (green) and 600/40 nm (red). Stained cells $(20 \mu \mathrm{l})$ were carefully spread onto a glass slide. After the $527 \mathrm{~nm}$ image (green image) was taken and saved, another image of the same field (same pellet) was acquired at $600 \mathrm{~nm}$ (red image). Photobleaching of the stained samples was considered as negligible because only a $5 \%$ decrease in fluorescence intensity was registered after five ratio measurements on the same field (10 successive excitations). Autofluorescence of the cells was shown to have no influence on the calculated ratio, since the mean fluorescence ratio at $527 / 600 \mathrm{~nm}\left(R_{527 / 600}\right)$ was $1.00(\mathrm{SD}<0.01)$ and pixel level intensity was inferior to image processing threshold values. No correlation could be found between ratio values and pellet size, suggesting that the methodology can be used for pellets of different sizes. For each experiment, 20-30 images were recorded at each emission wavelength. Error bars on the graphs represent the SD of mean $R_{527 / 600}$ values.

Image processing. An integrated controlled CCD monochrome camera (Cohu) was fitted onto the epifluorescence 
microscope. It was controlled via a PC through an acquisition card (Secad Vision) which allowed capture of $768 \times 576$ pixel TIFF images coded on 256 grey levels. The integration time was set to $25 \mathrm{~ms}$ for each image. Image treatment was carried out on a PC using professional image analysis software (Visilog; Noesis).

The aim was to obtain images with pixel values directly connected to the $\mathrm{pH}_{\mathrm{i}}$ value ( $\mathrm{pH}$ image) by using the double ratio technique described. The first part of the treatment deals with the segmentation of these images. This operation was carried out by an automatic thresholding technique based on image entropy. Concerning the image, entropy is maximum for an equally distributed grey level histogram and equal to zero for an image with only one grey level. This technique is used to segment images into two regions by maximizing the total entropy (Coster \& Chermant, 1989). It has been shown that such a segmentation best fits images containing pellets (Pons \& Vivier, 1999). Consequently, two binary images were obtained, one for each initial grey level image. The binary image only contains the relevant information (object), with pixels set to 1 and background pixels set to 0 . Then, a logical operation (intersection) between these images gives a single binary image representing the common part of the initial images. After morphological operations (dilation and reconstruction) to eliminate artefacts due to the thresholding, a final binary image is obtained and used as a mask for further operations. Masking is a point operation between a grey level and a binary image that produces a grey level image. In such an image, only pixel parts of the object (i.e. the pellet) are visible in grey level, the background pixels being set to black (0). Then, both grey level images (527 and $600 \mathrm{~nm}$ ) were masked and the mean grey levels of the pellets and the SD values were computed. These values are good indicators of the quality of calibration images and they were used as criteria for the final $\mathrm{pH}$ calculation. Finally, after transformation in floating point images to allow arithmetic operations, a pixel to pixel division between images was performed to get the $\mathrm{pH}$ image. Mean grey level and SD values were also calculated on this final image to give values related to $\mathrm{pH}_{\mathrm{i}}$.

Additional analytical methods. During batch fermentations samples were collected to determine glucose, pristinamycin and dry weight biomass levels.

$\mathrm{OD}_{660}$ was measured according to the method of Lubbe $e t$ al. (1985) by means of a Beckman spectrophotometer, DU 7500.

Dry weight biomass was determined gravimetrically by filtering $10 \mathrm{ml}$ fermentation broth on pre-weighed $0.45 \mu \mathrm{m}$ cellulose acetate membranes (Sartorius). Membranes were washed twice with $0.85 \% \mathrm{NaCl}$ and placed in an oven at $100{ }^{\circ} \mathrm{C}$ for $12 \mathrm{~h}$ before being weighed again. An $\mathrm{OD}_{660}$ vs dry weight correlation curve allowed dry weight biomass determination.

Pristinamycins were extracted and analysed by HPLC as described by Thibaut et al. (1995) with a Spectra-Physics HPLC system.

Glucose concentration was determined by HPLC according to the protocol described by Rondags et al. (1998).

\section{RESULTS}

\section{Method development}

Microscopic and morphological parameters. Due to the characteristics of the genus Streptomyces, S. pristinaespiralis tends to grow as a pellet of several hundred micrometres in submerged culture. Moreover, during

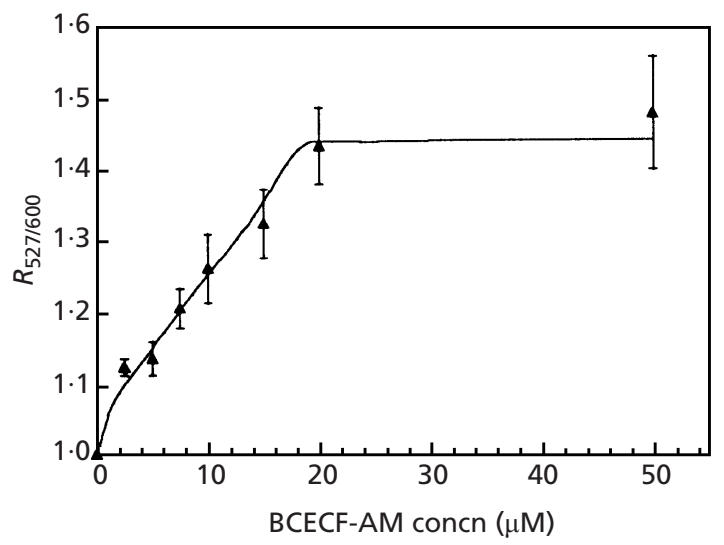

Fig. 1. $R_{527 / 600}$ of stained pellets $(30 \mathrm{~min}$ ) of $S$. pristinaespiralis as a function of BCECF-AM concentration.

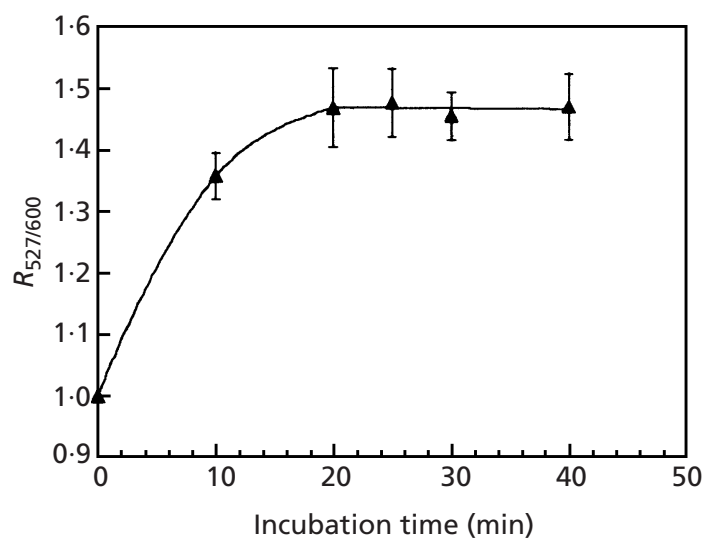

Fig. 2. $R_{527 / 600}$ of stained pellets of $S$. pristinaespiralis as a function of incubation time with $20 \mu \mathrm{M}$ BCECF-AM.

the pristinamycin production process, most of the cells are aggregated and form small pellets. Consequently, $\mathrm{pH}_{\mathrm{i}}$ was determined only on pellets, the predominant morphological form in this study.

Because magnifications of $\times 1000$ and $\times 400$ led to a dramatic photobleaching of the fluorescent probe, a final magnification of $\times 100$ was chosen. Using this magnification, a $25 \mathrm{~ms}$ exposure time was used to capture images.

Optimization of the BCECF-AM staining technique. The protocol for $\mathrm{pH}_{\mathrm{i}}$ measurement was first optimized by testing the effect of various dye concentrations and staining times on the measured fluorescence of S. pristinaespiralis. Cell samples were submitted to increasing concentrations of BCECF-AM, from 1 to $60 \mu \mathrm{M}$, for $30 \mathrm{~min}$ at $28^{\circ} \mathrm{C}$. The measured mean $R_{527 / 600}$ values of the samples are reported in Fig. 1.

For fluorochrome titres below $20 \mu \mathrm{M}$, the fluorescence ratio varies with the dye concentration, whereas at higher concentrations it remains rather constant. Because titres over $20 \mu \mathrm{M}$ gave an increasing SD and an 


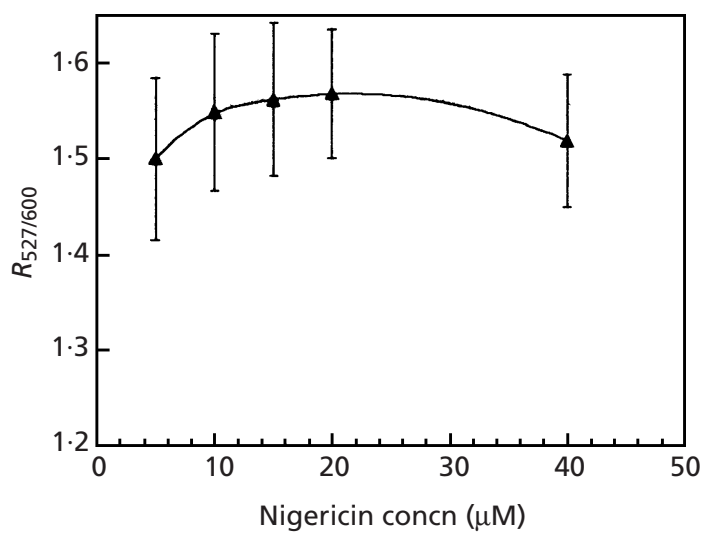

Fig. 3. $R_{527 / 600}$ of stained pellets $(20 \mu \mathrm{M}$ BCECF-AM, $30 \mathrm{~min})$ of $S$. pristinaespiralis suspended in $\mathrm{pH} 7.0$ high $\left[\mathrm{K}^{+}\right]$buffer as a function of nigericin concentration. The cells were incubated for $10 \mathrm{~min}$ with the ionophore.

important stain release, $20 \mu \mathrm{M}$ BCECF-AM was retained as a compromise concentration for further experiments. The optimized staining time with the fluorescent dye was determined using the same criteria (Fig. 2): $30 \mathrm{~min}$ staining was chosen for further experiments.

In vivo calibration. The effect of nigericin concentration was first assessed on stained samples suspended in high $\left[\mathrm{K}^{+}\right]$buffer ( $\mathrm{pH} 7 \cdot 0$ ) (Fig. 3). The optimal nigericin concentration was found to be $20-30 \mu \mathrm{M}$, since concentrations above or below reduced the $R_{527 / 600}$ values. Concentrations higher than $40 \mu \mathrm{M}$ led to cell lysis. However, the $R_{527 / 600}$ SD values found for different nigericin titres remained rather high. In addition, cell suspensions in high $\left[\mathrm{K}^{+}\right]$buffers at different $\mathrm{pH}$ values (ranging from 6.5 to 8.5 ) using only nigericin did not show a linear relationship between $R_{527 / 600}$ and external $\mathrm{pH}$.

Thus, the effect of simultaneous addition of $20 \mu \mathrm{M}$ nigericin and valinomycin concentrations ranging from 0 to $10 \mu \mathrm{M}$ on the $R_{527 / 600}$ values of the cells was assessed. It appeared that valinomycin at low concentrations had no significant influence on ratio values, but the heterogeneity of pellet $R_{527 / 600}$ values was diminished considerably, i.e. at $1 \mu \mathrm{M}$ valinomycin the SD of the mean ratio was reduced fivefold $(1 \cdot 41 \pm 0 \cdot 1)$ compared to the assay without valinomycin $(1.43 \pm 0.5)$. When higher valinomycin concentrations were used, dye was released, which considerably decreased the precision of the measurements. An investigation into the sequence of ionophore addition revealed that the best combination was a simultaneous addition of nigericin and valinomycin (data not shown). Thus, simultaneous addition of $20 \mu \mathrm{M}$ nigericin and $1 \mu \mathrm{M}$ valinomycin was chosen for further experiments.

To optimize the ionophore incubation time, suspensions of $S$. pristinaespiralis were stained with BCECF-AM and incubated with $20 \mu \mathrm{M}$ nigericin $/ 1 \mu \mathrm{M}$ valinomycin at $28{ }^{\circ} \mathrm{C}$ in high $\left[\mathrm{K}^{+}\right]$buffer $(\mathrm{pH} 7 \cdot 0)$ for times varying from 10 to $30 \mathrm{~min} . R_{527 / 600}$ was constant $(1 \cdot 46 \pm 0 \cdot 05)$ whatever

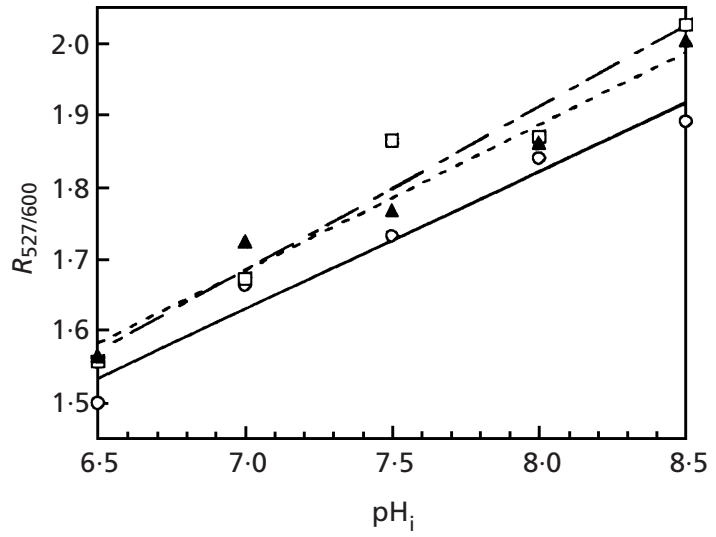

Fig. 4. Calibration curve of $S$. pristinaespiralis $\left(R_{527 / 600}\right.$ vs $\left.\mathrm{pH}_{\mathrm{i}}\right)$. The calibration curve was determined in triplicate using three different cultures of growing cells sampled after $24 \mathrm{~h}$.

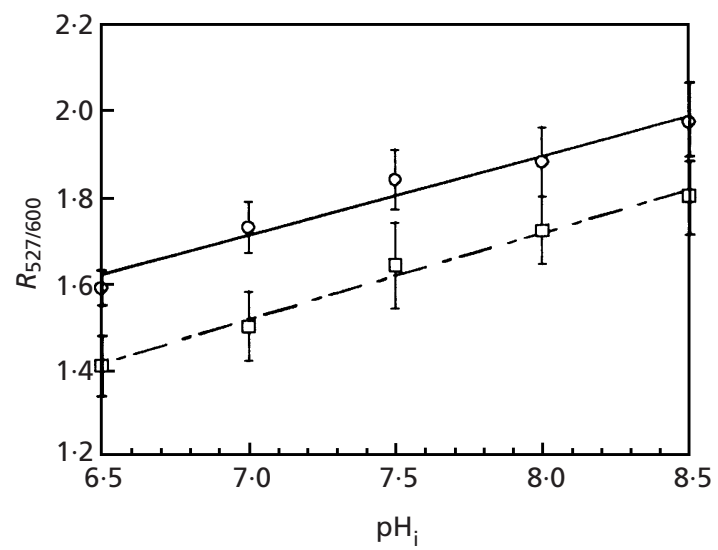

Fig. 5. Calibration curves for pellets having a mean $600 \mathrm{~nm}$ grey level ranging between 20 and $25(\square)$, and 25 and $30(\bigcirc)$.

incubation time was used. On this basis, a $10 \mathrm{~min}$ incubation time was chosen for further experiments.

For the calibration of the technique, cells were resuspended in high $\left[\mathrm{K}^{+}\right]$buffers at different $\mathrm{pH}$ values ranging from 6.5 to $8 \cdot 5$. The osmolality of the buffers was adjusted to that of the culture medium by means of xylose to avoid osmotic shock. Nigericin and valinomycin were added to the samples to equilibrate the $\mathrm{pH}_{\mathrm{i}}$ of the stained cells to the $\mathrm{pH}$ of the surrounding buffer.

Calibration curves - green/red fluorescence ratios vs $\mathrm{pH}-$ were established for three samples of growing cells sampled after $24 \mathrm{~h}$ culture (Fig. 4). After being captured by the monochrome camera, image analysis showed that the equation of the calibration curve was slightly different for pellets with grey level images between 20 and 25 , and between 25 and 30 , at $600 \mathrm{~nm}$. Thus, two calibration curves were used. One curve was drawn for pellets having mean grey levels between 20 and 25 at $600 \mathrm{~nm}$ and another was determined for mean grey levels between 25 and 30 (Fig. 5). For pellets with grey 
(a)

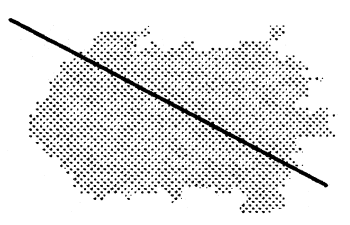

(b)

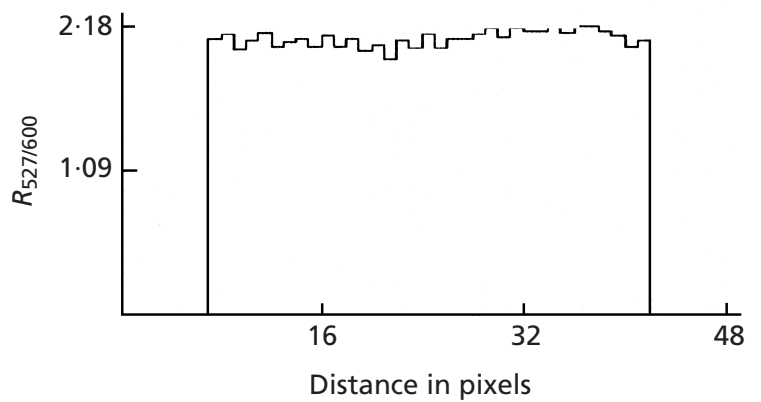

Fig. 6. $R_{527 / 600}$ profile along the straight line of a calibration $\mathrm{pH}$ image. (a) Line drawn on a pellet $\mathrm{pH}$ image. (b) $R_{527 / 600}$ values as a function of the distance in pixels along the straight line.

levels at 25 at $600 \mathrm{~nm}, \mathrm{pH}_{\mathrm{i}}$ values were calculated using both equations.

Interestingly, calibration curves established for bacteria sampled at different culture times showed the same relationship between $R_{527 / 600}$ and $\mathrm{pH}_{\mathrm{i}}$, indicating that the age of the $S$. pristinaespiralis culture has no influence on the in vivo calibration.

To investigate a possible effect of the three-dimensional size and shape of the pellets on axial resolution (depth of field), topographic sections across $\mathrm{pH}$ pellet images were taken (Fig. 6a). If there was an effect, a central pixel displaying a $\mathrm{pH}_{\mathrm{i}}$ similar to another at the periphery of the pellet would have a higher $R_{527 / 600}$. In fact, as shown in Fig. $6(\mathrm{~b})$, the mean $R_{527 / 600}$ values of the peripheral pixels (at the termini of the straight line) were identical to the values of the pixels from the centre of the pellet (middle of the line), indicating that the surface fluorescence is not affected by the depth of the pellet. Pellets presented a homogeneous $\mathrm{pH}_{\mathrm{i}}$ over a large part of their surface and the SD of mean $R_{527 / 600}$ values for pixels of a given $\mathrm{pH}_{\mathrm{i}}$ remained very low over the whole surface of the pellets.

Using these experimental conditions, $\mathrm{pH}_{\mathrm{i}}$ was determined with satisfactory precision, since the error did not exceed $0.3 \mathrm{pH}$ units for $\mathrm{pH}_{\mathrm{i}}$ values between 6.5 and 8.5.

\section{Bioreactor batch culture of pristinamycin-producing S. pristinaespiralis}

The protocol presented for $\mathrm{pH}_{\mathrm{i}}$ determination was applied to the pristinamycin-producing $S$. pristinaespiralis grown under stable $\mathrm{pH}$ conditions (external

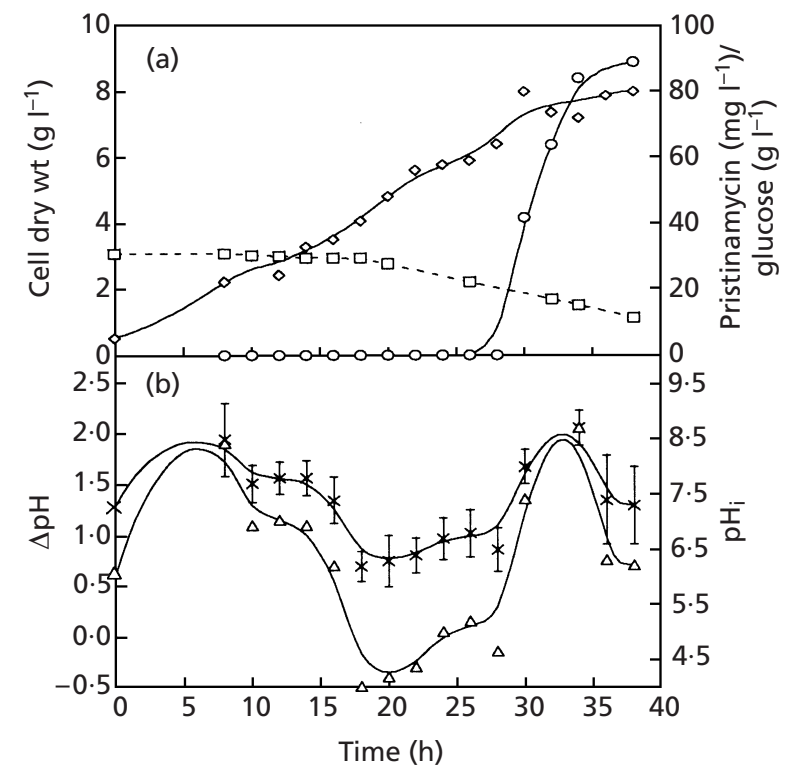

Fig. 7. Properties of $S$. pristinaespiralis cultivated in batch mode in a $2 \mathrm{I}$ bioreactor. (a) Dry weight biomass $(\diamond)$, glucose concentration $(\square)$ and pristinamycin profiles $(O)$. (b) $\mathrm{pH}_{\mathrm{i}}(\times)$ and $\Delta \mathrm{pH}(\triangle)$ profiles. Error bars represent the SD of mean $\mathrm{pH}_{\mathrm{i}}$ values. Thirty pellet images were recorded at each wavelength.

pH 6.8). To evaluate growth, glucose consumption, pristinamycin production and $\mathrm{pH}_{\mathrm{i}}$ of $S$. pristinaespiralis, a bioreactor was operated in batch mode over a $40 \mathrm{~h}$ period (Fig. $7 \mathrm{a}, \mathrm{b})$. The $\mathrm{pH}_{\mathrm{i}}$ of the pellets of each culture sample was calculated with the calibration curve corresponding to the mean grey level at $600 \mathrm{~nm}$. The dry weight biomass level, initially $0.4 \mathrm{~g} \mathrm{l}^{-1}$, increased to reach a maximum of $8 \cdot 0 \mathrm{~g} \mathrm{l}^{-1}$ within $40 \mathrm{~h}$ (Fig. 7a). Growth stopped independently of carbon limitation as the glucose concentration was still around $20 \mathrm{~g} \mathrm{l}^{-1}$ at that time.

Contrary to the external $\mathrm{pH}, \mathrm{pH}_{\mathrm{i}}$ showed important variations during the course of fermentation (Fig. $7 \mathrm{~b}$ ). Starting from an initial value of $7 \cdot 2, \mathrm{pH}_{\mathrm{i}}$ quickly increased to values around $8 \cdot 2$ during the first $10 \mathrm{~h}$. Then it dramatically decreased, to reach $6 \cdot 2$ after $17 \mathrm{~h}$ culture. This value remained stable for a $10 \mathrm{~h}$ period and finally came back to near its initial value during the last period of the process. Further $\mathrm{pH}_{\mathrm{i}}$ determinations during the stationary phase were not possible due to significant probe leakage. Because the extracellular $\mathrm{pH}$ was quite constant around $6 \cdot 8$, the $\mathrm{pH}_{\mathrm{i}}$ and $\Delta \mathrm{pH}$ profiles were similar during the batch process. As seen, the cells were capable of maintaining a positive $\Delta \mathrm{pH}$ throughout the culture period, except during the $10 \mathrm{~h}$ period preceding the excretion phase.

This culture was performed in triplicate (data not shown) and identical $\mathrm{pH}_{\mathrm{i}}$ profiles were observed, though minor differences regarding the $\mathrm{pH}_{\mathrm{i}}$ values were obtained during the three processes $( \pm 0.4 \mathrm{pH}$ units $)$. 


\section{DISCUSSION}

The first aim of this study was to develop a new method for the measurement of $\mathrm{pH}_{\mathrm{i}}$ in filamentous streptomycetes. Because flow cytometry cannot be used for filamentous bacteria, and NMR or radiolabelled weak acid/base distribution analyses are even more difficult and tedious techniques requiring high cell densities and specific materials, an image-analysis-based fluorometric method was developed.

The fluorochrome BCECF-AM, with a $\mathrm{p} K_{\mathrm{a}}$ of $7 \cdot 0$, was found to be efficient for $\mathrm{pH}_{\mathrm{i}}$ determination of neutrophilic bacteria, such as $S$. pristinaespiralis, grown in a bioreactor: the fluorescence was proportional to the $\mathrm{pH}_{\mathrm{i}}$ of the cells between $\mathrm{pH}$ values of 6.5 and 8.5 , and the fluorescence of the stained cells was stable for at least 30 min.

During this study only pellets of $S$. pristinaespiralis were taken into account because the bacteria mainly grow in this form during the pristinamycin-producing process. Another reason for this choice is that the origin of dispersed filaments present in the culture medium is not always clear. They can be present as a consequence of the alteration of fluffy pellets caused by shearing forces produced by the increased agitation necessary for the regulation of dissolved oxygen. Moreover, simultaneous analysis of all morphologies present in the culture has been reported to be impossible since a $\times 100$ oil immersion objective $(\times 1000$ final magnification) generally requires the use of coverslips for filament analysis which can disturb the physiology of the cells in the pellets (Nielsen et al., 1995; Cox et al., 1998).

The $\mathrm{pH}_{\mathrm{i}}$ of $S$. pristinaespiralis cells only from the surface of the pellets (projected area) was considered. In fact, surface cells within the pellets can be considered as the most active cells because pellets have been described to have hollows in their centre (Thomas, 1992). These hollows form due to cell necrosis as a result of limitations in oxygen and nutrients.

In vivo calibration is essential to avoid response variability due to differences in microscope focusing between BCECF solutions (in vitro calibration) and BCECF-AMstained pellets.

Satisfactory correlation coefficients and linearity were found with the proposed nigericin-valinomycin protocol over the $\mathrm{pH} 6.5-8.5$ range. Contrary to the results of Boyarsky et al. (1996a, b) using eukaryotes, enough $\mathrm{K}^{+}$ was able enter the pellets to equilibrate extracellular and $\mathrm{pH}_{\mathrm{i}}$, even at basic $\mathrm{pH}$ values. Addition of xylose, resulting in increased osmolality of high $\left[\mathrm{K}^{+}\right]$buffers, could be used to avoid $\mathrm{K}^{+}$efflux in response to hypotonic shock. Such inward or outward cationic fluxes have been described in response to medium osmolality changes (Guillouet, 1996). One explanation for the efficient combination of valinomycin and nigericin at these concentrations could be their overwhelming action on mechanisms of cell regulation, allowing equal distribution of $\mathrm{K}^{+}$at intracellular and extracellular levels, without any residual $\mathrm{K}^{+}$gradient, contrary to the results of Boyarsky et al. (1996a, b).

Slight differences in $600 \mathrm{~nm}$ pixel intensity for images of pellets resuspended in buffer with the same $\mathrm{pH}$ could generate slightly different $R_{527 / 600}$ ratios, as seen during this study. Differences in staining have been reported for cells having different esterase activities in the culture (Franck et al., 1996). However, the difference in $527 \mathrm{~nm}$ fluorescence should have been of the same order. One explanation could be a different sensitivity of the camera, which is described as more efficient around 527 $\mathrm{nm}$, at the two wavelengths. Another reason is that $600 / 40 \mathrm{~nm}$ fluorescence is not really an isosbestic point (Franck et al., 1996). Actually, this artefact could be corrected using two different calibration curves, according to the level of fluorescence at $600 \mathrm{~nm}$.

The advantage of the image analysis algorithm developed here is that it does not modify any pixel level. This results in the collection of unmodified data and it gives a more accurate estimation of actual $\mathrm{pH}_{\mathrm{i}}$. Since fluorescence was pellet-area-independent, contrary to other studies dealing with morphology by image analysis (Sieracki et al., 1989; Durant et al., 1994a, b), no delimitation problems were encountered by using an automated entropy threshold. The simplicity and rapidity (less than $1 \mathrm{~min}$ for calculation) of this procedure are favourable to on-line routine analysis during fermentation processes.

This paper presents for the first time a method for the determination of $\mathrm{pH}_{\mathrm{i}}$ of filamentous bacteria by means of epifluorescence microscopy and image analysis using a $\mathrm{pH}$-sensitive fluorescent probe. Although a positive control was not employed during this study (use of a bacterium with a known $\mathrm{pH}_{\mathrm{i}}$ ), the different tools and techniques utilized have already been reported to be efficient for the determination of $\mathrm{pH}_{\mathrm{i}}$ in bacteria. First, BCECF is a valuable fluorochrome to determine $\mathrm{pH}_{\mathrm{i}}$ since it has been shown to perfectly corroborate ${ }^{31} \mathrm{P}-$ NMR spectroscopy data obtained for Propionibacterium acnes (Futsaether et al., 1993). Moreover, Slavik (1997) has shown that the BCECF emission ratio technique can be employed for confocal microscopy to determine $\mathrm{pH}$. In addition, $\mathrm{pH}_{\mathrm{i}}$ determination of Listeria innocua using epifluorescence microscopy and image analysis (Siegumfeldt et al., 1999) confirmed the results obtained by spectrofluorimetry (Breeuwer et al., 1996).

During this study, the $\mathrm{pH}_{\mathrm{i}}$ of $S$. pristinaespiralis grown in batch culture was measured by an image analysisbased method using the fluorochrome BCECF-AM at a final concentration of $20 \mu \mathrm{M}$ at $28^{\circ} \mathrm{C}$ and for $30 \mathrm{~min}$. As shown, $\mathrm{pH}_{\mathrm{i}}$ could be correlated to pristinamycin excretion and glucose consumption in batch process. In fact, $\mathrm{pH}_{\mathrm{i}}$ was found to be a good marker of the physiological state of the cells cultivated under pristinamycin-producing conditions. Furthermore, $\mathrm{pH}_{\mathrm{i}}$ assessment can contribute to the understanding of variations in carbon fluxes through the enzymes involved in glucose metabolism, and $\Delta \mathrm{pH}$ calculation may help in the 
establishment of kinetic models for excretion and consumption of metabolites. Finally, the new method presented in this paper for $\mathrm{pH}_{\mathrm{i}}$ assessment of $S$. pristinaespiralis could be extended to filamentous bacteria of fungal cells cultivated in vitro, provided that the staining protocol was adapted to each cell line.

\section{ACKNOWLEDGEMENTS}

The authors express their gratitude to Dr M. N. Pons for her expert remarks and advice and to the Rhone-Poulenc-Rorer company (Vitry-France) for providing the micro-organism. This research was supported by the Ministere de l'Education Nationale de la Recherche et de la Technologie.

\section{REFERENCES}

Baltz, R. H. (1998). Genetic manipulation of antibiotic-producing Streptomyces. Trends Microbiol 6, 76-83.

Boyarsky, G., Hanssen, C. \& Clyne, L. A. (1996a). Inadequacy of high $\mathrm{K}^{+} /$nigericin for calibrating BCECF II. Intracellular pH dependence of the correction. Am J Physiol 271, 1146-1156.

Boyarsky, G., Hanssen, C. \& Clyne, L. A. (1996b). Superiority of in vitro over in vivo calibrations of BCECF in vascular smooth muscle cells. FASEB J 10, 1205-1212.

Breeuwer, P., Drocourt, J. L., Rombouts, F. M. \& Abee, T. (1996). A novel method for continuous determination of the intracellular $\mathrm{pH}$ in bacteria with the internally conjugated fluorescent probe 5 (and 6-)-carboxyfluorescein succinimidyl ester. Appl Environ Microbiol 62, 178-183.

Cherlet, M., Franck, P., Nabet, P. \& Marc, A. (1999). Development and validation of a methodology for intracellular $\mathrm{pH}$ measurements of hybridoma cells under bioreactor culture conditions. Biotechnol Prog 15, 630-639.

Coster, M. \& Chermant, J. P. (1989). Traitement des images en niveau de gris. In Précis d'Analyse d'Images, pp. 387-395. Paris: Presse du CNRS.

Cox, P. W. \& Thomas, C. R. (1992). Classification and measurement of fungal pellets by automated image analysis. Biotechnol Bioeng 39, 945-952.

Cox, P. W., Paul, G. C. \& Thomas, C. R. (1998). Image analysis of the morphology of filamentous micro-organisms. Microbiology $144,817-827$.

Craig, W. A. (1996). Antimicrobial resistance issues of the future. Diagn Microbiol Infect Dis 25, 213-217.

Demain, A. L. (1972). Cellular and environmental factors affecting the synthesis and excretion of metabolites. J Appl Chem Biotechnol 22, 345-362.

Demain, A. L. (1999). Pharmaceutically active secondary metabolites of micro-organisms. Appl Microbiol Biotechnol 52, 455-463.

Dix, A. \& Verkman, A.S. (1990). Mapping of fluorescence anisotropy in living cells by ratio imaging. Application to cytoplasmic viscosity. Biophys J 57, 231-240.

Drouin, J. F., Louvel, L., Vanhoutte, B., Vivier, H., Pons, M. N. \& Germain, P. (1997). Quantitative characterization of cellular differentiation of Streptomyces ambofaciens in submerged culture by image analysis. Biotechnol Tech 11, 819-824.

Durant, G., Cox, P. W., Formisyn, P. \& Thomas, C. R. (1994a). Improved image analysis algorithm for the characterization of mycelial aggregates after staining. Biotechnol Tech 8, 759-764.

Durant, G., Crawley, G. \& Formisyn, P. (1994b). A simple staining procedure for the characterization of basidiomycetes pellets by image analysis. Biotechnol Tech 11, 395-400.

Franck, P., Petitpain, N., Cherlet, M., Dardenne, M., Maachi, F., Schutz, B., Poisson, L. \& Nabet, P. (1996). Measurement of intracellular $\mathrm{pH}$ in cultured cells by flow cytometry with BCECFAM. J Biotechnol 46, 187-195.

Futsaether, C. M., Kjeldstad, B. \& Johnson, A. (1993). Measurement of the intracellular $\mathrm{pH}$ of Propionibacterium acnes: comparison between the fluorescent probe BCECF and ${ }^{31} \mathrm{P}-$ NMR spectroscopy. Can J Microbiol 39, 180-186.

Guillouet, S. (1996). Etude cinétique et physiologique de Corynebacterium glutamicum sous stress osmotique. PhD thesis, INPLNancy, France.

Heiple, J. M. \& Taylor, D. L. (1980). Intracellular $\mathrm{pH}$ in single motile cells. J Cell Biol 86, 885-890.

Imai, T. \& Ohno, T. (1995). Measurement of yeast intracellular $\mathrm{pH}$ by image processing and the change it undergoes during growth phase. J Biotechnol 38, 165-172.

Leyval, D., Debay, F., Engasser, J. M. \& Goergen, J. L. (1997). Flow cytometry for the intracellular $\mathrm{pH}$ measurement of glutamate producing Corynebacterium glutamicum. J Microbiol Methods 29, 121-127.

Lubbe, C., Demain, A. L. \& Bergman, K. (1985). Use of controlledrelease polymer to feed ammonium to Streptomyces clavuligerus cephalosporin fermentations in shake flasks. Appl Microbiol Biotechnol 22, 424-427.

Mauss, P., Drouin, J. F., Pons, M. N., Vivier, H., Germain, P., Louvel, L. \& Vanhoutte, B. (1997). Location of respiration activity in filamentous bacteria by image analysis. Biotechnol Tech 11, 813-817.

Musgrove, E., Rugg, C. \& Hedley, D. (1986). Flow cytometry measurement of cytoplasmic $\mathrm{pH}$ : a critical evaluation of available fluorochromes. Cytometry 7, 347-355.

Nielsen, J., Johansen, C. L., Jacobsen, M., Krabben, P. \& Villadsen, J. (1995). Pellet formation and fragmentation in submerged cultures of Penicillium chrysogenum and its relation to penicillin production. Biotechnol Prog 11, 93-98.

Paquet, v. (1990). Mise en evidence de facteurs d'induction de la production de pristinamycines chez Streptomyces pristinaespiralis. PhD thesis, INSA, Toulouse, France.

Paradiso, A. M., Tsien, R. Y. \& Machen, T. E. (1987). Digital image processing of intracellular $\mathrm{pH}$ in gastric oxyntic and chief cells. Nature 325, 447-450.

Paul, G. C. \& Thomas, C. R. (1998). Characterization of mycelial morphology using image analysis. Adv Biochem Eng Biotechnol 60, 1-59.

Pons, M. N. \& Vivier, H. L. (1999). Biomass quantification by image analysis. Adv Biochem Eng Biotechnol 66, 135-183.

Pons, M. N., Drouin, J. F., Louvel, L., Vanhoutte, B., Vivier, H. \& Germain, P. (1998). Physiological investigations by image analysis. J Biotechnol 65, 3-14.

Pressman, B. C. (1976). Biological applications of ionophores. Annu Rev Biochem 45, 501-530.

Preud'homme, J., Tarridec, P. \& Belloc, A. (1968). Pristinamycine: isolement, caractérisation et identification des constituants. Bull Soc Chim Fr 2, 585-591.

Rhône-Poulenc (1961). Procédé de préparation d'un antibiotique par une nouvelle souche de Streptomyces. French Patent no. 1301-857.

Rondags, E., Halliday, E. \& Marc, I. (1998). Diacetyl production mechanism by a strain of Lactococcus lactis spp lactis bv. 
diacetylactis. Study of $\alpha$-acetolactic acid extracellular accumulation under anaerobiosis. Appl Biochem Biotechnol 69, 113-125.

Siegumfeldt, H., Rechinger, K. B. \& Jakobsen, M. (1999). Use of fluorescence ratio imaging for intracellular $\mathrm{pH}$ determination of individual bacteria cells in mixed cultures. Microbiology 145, 1703-1709.

Sieracki, M. E., Reichenbach, S. E. \& Webb, K. L. (1989). Evaluation of automated threshold selection methods for accurately sizing microscopic fluorescent cells by image analysis. Appl Environ Microbiol 55, 2762-2772.

Slavik, J. (1983). Intracellular $\mathrm{pH}$ topography: determination by a fluorescent probe. FEBS Lett 156, 227-230.

Slavik, J. (1997). Application of fluorescent probes in cellular biology. Measurement of intracellular pH. J Lumin 72, 575-577.

Thibaut, D., Ratet, N., Bisch, D., Faucher, D., Debussche, L. \& Blanche, F. (1995). Purification of the two-enzyme system catalysing the oxidation of the D-proline residue of pristinamycin $\mathrm{II}_{\mathrm{B}}$ during the last step of pristinamycin $\mathrm{II}_{\mathrm{A}}$ biosynthesis. $J$ Bacteriol 177, 5199-5205.

Thomas, C. R. (1992). Image analysis: putting filamentous microorganisms in the picture. Trends Biotechnol 10, 343-348.

Videau, D. (1982). Etude de l'activité bactéricide de la pristinamycine. Pathol Biol 30, 529-534.

Whitaker, A. (1991). Actinomycetes in submerged culture. Appl Biochem Biotechnol 32, 23-35.

Yang, K. Y., Morikawa, M., Shimizu, H., Shioya, S., Suga, K. I., Nihira, T. \& Yamada, Y. (1996). Image analysis of mycelial morphology in virginiamycin production by batch culture of Streptomyces virginiae. J Ferment Bioeng 81, 7-12.

Received 14 March 2000; revised 19 June 2000; accepted 12 July 2000. 